\title{
Enhanced Activation of NMDA Receptor Responses at the Immature Retinogeniculate Synapse
}

\author{
Ary S. Ramoa and David A. McCormick \\ Section of Neurobiology, Yale University School of Medicine, New Haven, Connecticut 06510
}

The maturation of retinogeniculate excitatory transmission and intrathalamic inhibition was studied in slices of the dorsal LGN obtained from ferrets during the first 2 postnatal months. Response to optic tract stimulation at neonatal ages consisted of slow EPSPs lasting several hundred milliseconds. Application of the NMDA receptor antagonist D-(-)-2amino-5-phosphonovaleric acid (D-APV) during the first 2 postnatal weeks resulted in EPSPs that were reduced in peak amplitude and dramatically curtailed in duration, indicating that NMDA receptors participate strongly in retinogeniculate transmission at the immature synapse. Gradually, EPSPs became shorter in duration such that after the second postnatal week, the retinogeniculate EPSPs were only a few milliseconds in duration. At this late stage of development responses were remarkably less affected by application of D-APV. These changes in contribution of NMDA receptors to retinogeniculate transmission were found to be due to the development of strong IPSPS, the result of gradual maturation of activation of GABAergic inhibition. Indeed, application of bicuculline methiodide to block GABA $_{A}$ receptor-mediated IPSPS strongly enhanced the NMDA component of the EPSPs in more mature cells.

The voltage dependence and kinetics of NMDA-induced excitatory postsynaptic currents (NMDA EPSCs) were characterized by voltage-clamp recordings after blocking AMPA/ kainate receptors with 6-cyano-7-nitroquinoxaline-2,3-dione and $\mathrm{GABA}_{\mathrm{A}}$ receptors with bicuculline methiodide. The voltage dependence of the NMDA EPSCs remained unaltered with age. During the first postnatal month the kinetic properties of the NMDA EPSCs also remained unaltered, but a reduction in EPSC duration was observed within the following weeks, well after the critical period of anatomical reorganization.

The present results demonstrate that the contribution of NMDA ionophores to retinogeniculate transmission is enhanced during the developmental critical period of remodeling in retinogeniculate connectivity. This transient enhancement appears to result largely from the late development of GABAergic inhibition, although changes in intrinsic membrane properties and properties of the NMDA ionophore may also contribute. Enhanced contribution of

Received Apr. 26, 1993; revised Sept. 15, 1993; accepted Sept. 29, 1993

This work was supported by NIH. We thank Dr. Arnold Kriegstein for his conlributions to this project.

Correspondence should be addressed to Ary S. Ramoa, Virginia Commonwealth University, Medical College of Virginia, Department of Anatomy, Box 709, Richmond, VA 23298-0709.

Copyright (C) 1994 Society for Neuroscience $0270-6474 / 94 / 142098-08 \$ 05.00 / 0$
NMDA receptors may facilitate anatomical rearrangements of retinogeniculate connections during development.

[Key words: NMDA response, lateral geniculate nucleus, development, intrathalamic inhibition, ferret, patch-clamp technique, slice preparation]

The dorsal lateral geniculate nucleus (LGNd) in ferrets, cats, nonhuman primates, and humans is characterized by a laminar organization, each lamina consisting of groupings of cell somata that make synaptic contact with a single retina (Hickey and Guillery, 1974; Rakic, 1976; Shatz, 1983). This arrangement is not present during early development, when retinogeniculate connections are diffuse and intermixed, displaying extensive overlap of the contra- and ipsilateral retinal fibers (Rakic, 1976; Linden et al., 1981; Shat $z, 1983$ ). In the ferret, complete segregation of retinal afferents from each eye occurs concurrently with the cytoarchitectonic differentiation of the LGNd layers, during approximately the first 2 postnatal weeks. Retinogeniculate connections in the ferret then remodel further during the third postnatal week by segregation of on-center and off-center retinal axons into sublaminae within the dorsal laminae (Stryker and Zahs, 1983; Hahm et al., 1991). Acquisition of the precise pattern of adult connectivity thus requires extensive remodeling of connections, probably involving elimination of inappropriate synapses (Campbell and Shatz, 1992).

Analogy with other systems suggests that synaptic plasticity in retinothalamic connections depends on activation of NMDA receptors (Constantine-Paton et al., 1990). Some evidence has been obtained for this possibility: both NMDA and non-NMDA glutamate receptors contribute to retinogeniculate transmission in the adult cat and ferret LGNd (Kemp and Sillito, 1982; Scharfman et al., 1990; Esguerra et al., 1992), blockade of NMDA receptors on LGNd cells prevents the formation of "On" and "Off" sublamination (Hahm et al., 1991) and recent experiments have indicated that plasticity at the retinogeniculate synapse may involve activation of NMDA receptors (Mooney et al. 1993).

To explain the greater plasticity that characterizes developing synapses, it has been suggested that the participation of NMDA receptors in synaptic activity is enhanced at early stages of development (Tsumoto et al., 1987; Fox et al., 1989; Kleckner and Dingledine, 1991; Siviy et al., 1991; Hestrin, 1992). Mechanisms that have been proposed for this enhancement include changes in the number of receptors (Garthwaite et al., 1987; Bode-Greucl and Singer, 1989; Trembley et al., 1989), their response properties (Cambray-Deakin et al., 1990; but see Blanton et al., 1990), or late development of GABAergic inhibition (Luhman and Prince, 1990; Agmon and O'Dowd, 1993; Burgard 
P4

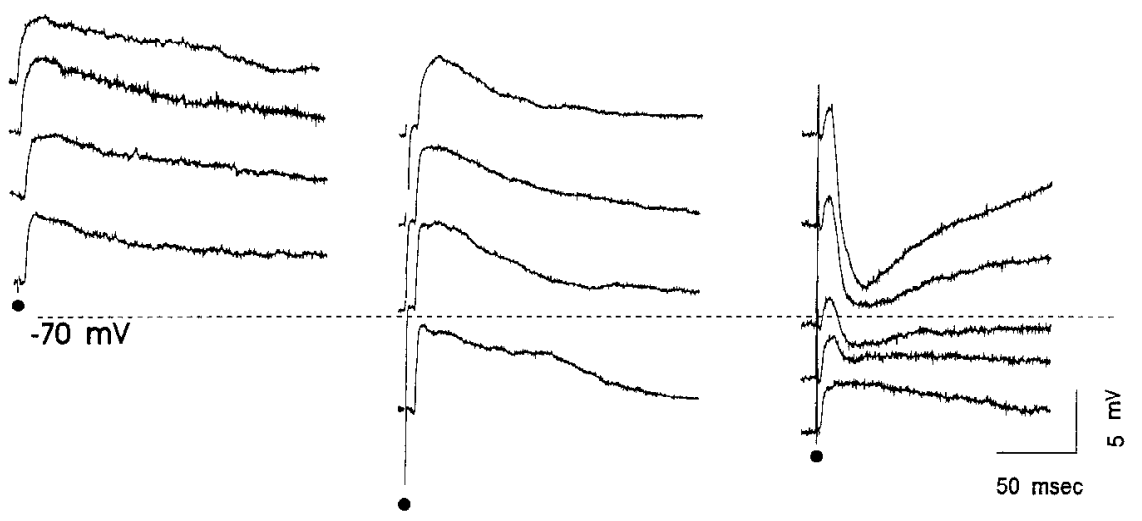

Figure 1. EPSPs and IPSPs evoked by electrical stimulation of the optic tract in three LGNd neurons at different stages of development. Recordings at different membrane potentials revealed the presence of slow EPSPs lasting hundreds of milliseconds in immature neurons. In contrast, the P21 cell displayed a relatively short-duration EPSP followed by a strong IPSP. These examples suggest that IPSPs mature relatively late during development. Single shock stimulation $(0.1 \mathrm{msec})$ applied to optic tract at the dot. and Hablitz, 1993). For instance, NMDA receptors in young rat brain have been found to be more sensitive to activation by glycine (Kleckner and Dingledine, 1991) and less sensitive to blockade by $\mathrm{Mg}^{2+}$ (Bowe and Nadler, 1990; Morrisett et al., 1990; Kleckner and Dingledine, 1991) than NMDA receptors found in the mature state. Moreover, recent experiments have suggested that kinetic properties of NMDA-mediated synaptic currents display substantial changes with development (Carmignoto and Vicini, 1992; Hestrin, 1992).

To examine the properties of transmission in the developing retinogeniculate synapse, we recorded from immature LGNd neurons using the in vitro slice preparation. Thalamic slices were obtained from animals ranging in age from day of birth (postnatal day $0, \mathrm{P} 0$ ), when retinogeniculate connections are diffuse and intermixed (Linden et al., 1981), until P54, after morphologically mature cell types can be recognized in the LGNd (Sutton and Brunso-Bechtold, 1991), retinogeniculate connections have segregated according to eye of origin (Linden et al., 1981), eyelids have opened, and mature electrophysiological properties of I.GNd cells have been established (Ramoa and McCormick, 1994). We were especially interested in examining the relative contribution and properties of NMDA receptor-mediated responses to retinogeniculate synaptic activation in the developing LGNd, and the regulation of this by GABAergic inhibition.

The results of this work have been presented in prelininary form (Ramoa and McCormick, 1992).

\section{Materials and Methods}

Preparations were as described in the preceding companion article (Ramoa and McCormick, 1994), except that in some experiments, noted in the text and in the figure captions, the concentration of $\mathrm{MgSO}_{4}$ was raised to $4 \mathrm{~mm}$. Recordings were conducted in the current-clamp mode at a tcmpcrature of $32^{\circ} \mathrm{C}$, and in the voltage-clamp mode at a temperature of $22^{\circ} \mathrm{C}$.

To activate retinal afferents to the LGNd, constant current stimuli (100 $\mu \mathrm{sec}$ duration) were delivered through a bipolar stimulating electrode positioned in the optic tract at the ventralmost aspect of the LGNd slice. Electrical stimuli varying from 30 to $1000 \mu \mathrm{A}$ in intensity were applied at $10-20 \mathrm{sec}$ intervals. Repetitive stimuli consisted of trains of 3-10 pulses at frequencies ranging from 5 to $100 \mathrm{~Hz}$. Trains were separated by $30-60$ sec intervals.

The following compounds were applied in the bathing solution in some experiments: D-(-)-2-amino-5-phosphonovaleric acid (D-APV), 6-cyano-7-nitroquinoxaline-2,3-dione (CNQX), and (-)-bicuculline methiodide (Sigma).

\section{Results}

Synaptic responses evoked by electrical stimulation (30-1000 $\mu \mathrm{A})$ of the optic tract as seen in current-clamp $\left(32^{\circ} \mathrm{C}\right.$, potassium gluconate pipette solution) and voltage-clamp $\left(22^{\circ} \mathrm{C}\right.$, cesium gluconate pipette solution) modes were recorded in $92 \mathrm{LGNd}$ neurons from postnatal ages P0-P54.

\section{Recordings in current-clamp mode}

Late maturation of GABAergic inhibition. Postsynaptic responses representative of neurons at different developmental stages are shown in Figure 1. Electrical stimulation of the optic tract at P21 evoked a monosynaptic excitatory potential that was followed by a strong IPSP with a reversal potential of approximately $-73 \mathrm{mV}$. At earlier ages, in contrast, the excitatory response was extremely prolonged and was generally not followed by hyperpolarizing IPSPs. Indeed, hyperpolarizing IPSPs were not observed in cells recorded during the first postnatal week even when resting membrane potential was depolarized to levels near firing threshold (Fig. 1, P4), or when stimulus intensity was reduced (not shown), a procedure that has been reported to reveal IPSPs in the absence of a preceding EPSP in adult animals (Crunelli et al., 1988). The examples of postsynaptic response shown in Figure 1 indicate that activation of GABAergic inhibition may mature relatively late during development of the ferret LGNd.

Additional evidence for this conclusion was obtained by application of bicuculline methiodide to block $\mathrm{GABA}_{\mathrm{A}}$ receptors. Examples of the results obtained at different ages are shown in Figure $2 A-C$. At $P 4$, optic tract stimulation induced a slow EPSP with a long decay time that remained relatively unaltered after complete block of $\mathrm{GABA}_{\mathrm{A}}$ receptors through bath application of bicuculline methiodide ( $50 \mu \mathrm{M}$; Fig. $2 A$, bicuculline). At P21 bicuculline blocked the IPSP, revealing an optic tract response that resembled that of the more immature neuron (Fig. 2B). Later in development, at P30, the first IPSP was usually followed by a slower, longer-lasting IPSP that displayed a more negative reversal potential (approximately $-80 \mathrm{mV}$ in contrast with about $-65 \mathrm{mV}$ for the $\mathrm{GABA}_{\mathrm{A}}$-mediated IPSP). The late IPSP was blocked by the $\mathrm{GABA}_{\mathrm{B}}$ antagonist 2-hydroxy saclofen (300-500 $\mu \mathrm{M})$ applied in the bathing medium ( $n=3$; not shown). As shown in Figure $2 C$, bicuculline methiodide blocked the first IPSP present at P30 while actually increasing the amplitude of the slower IPSP. 
A

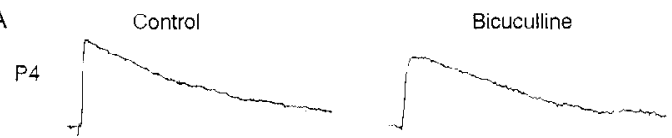

B
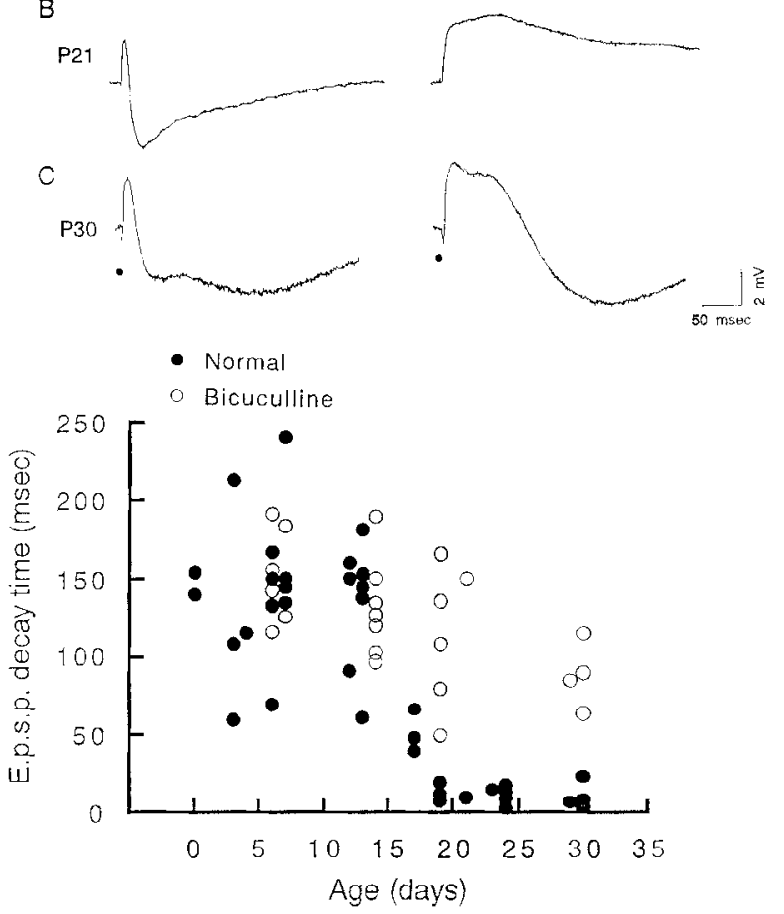

Figure 2. Examples of responses to clectrical stimulation of the optic tract in three LGNd cells at P4, P21, and P30 before and after application of the $\mathrm{GABA}_{\mathrm{A}}$ receptor antagonist bicuculline methiodide $(40 \mu \mathrm{M})$ to the bathing medium. The slow EPSP at P4 was not affected by bicuculline methiodide. In contrast, at the older ages bicuculline blocked the $\mathrm{GABA}_{\mathrm{A}}$ component of the inhibitory potentials, and resulted in prolongation of the preceding EPSP. The plot shows EPSP decay time plotted against postnatal age for 38 neurons studied before application of bicuculline methiodide (solid symbols) and for 23 ncurons in the presence of bicuculline (open symbols). Note the dramatic decrease in EPSP duration that occurred during the first 3 postnatal weeks. These changes result largely from the maturation of GABAergic mechanisms, since long-lasting EPSPs were revealed in the older cells recorded in the presence of bicuculline. All recordings were conducted at resting potential level for each cell $(\mathrm{P} 4=-54 \mathrm{mV}, \mathrm{P} 21=-62 \mathrm{mV}, \mathrm{P} 30=-63$ $\mathrm{mV}$ ).

Population analysis of the changes in synaptic responses with age and of the role that GABAergic mechanisms play in sculpting optic tract evoked EPSPs is provided in the plot of Figure $2 C$. Duration of EPSPs was estimated by computing for each cell a standardized measure of decay time based upon the time from the peak of the EPSP to 0.37 (1/e) of the peak amplitude. Note the progressive reduction in EPSP duration that occurs mainly during the first 3 postnatal weeks (solid symbols). Recordings conducted in the presence of bicuculline methiodide (open symbols) indicate that reduction in EPSP duration results in large part from maturation of $\mathrm{GABA}_{\mathrm{A}}$ receptor-mediated inhibitory interactions. GABAergic inhibition initially had a relatively small role in geniculate synaptic responses, since EPSP decay times were similar in control and bicuculline-treated cells. After the second postnatal week, in contrast, EPSPs recorded after application of bicuculline were remarkably longer lasting than found in untreated cells.
NMDA component of the optic tract response. To examine the contribution of NMDA receptors to the optic tract response present in immature LGNd neurons, slices were perfused with the NMDA receptor antagonist D-APV. As illustrated in Figure $3 A$, block of NMDA receptors with D-APV substantially reduced the duration, and slightly reduced the peak amplitude of retinogeniculate EPSPs present at P6. Recordings obtained from the same neuron during repetitive stimulation of the optic tract are also shown in Figure 3A. In spite of the smaller amplitude of each successive single EPSP, repetitive stimulation at P6 (frequency of $25 \mathrm{~Hz}$ ) induced progressive depolarization of the LGNd cell, generating a "staircase" appearance. This was mainly the result of superposition of each new response with the long tail of the preceding EPSP. Application of D-APV (50-100 $\mu \mathrm{M})$ revealed that interactions depend on activation of NMDA receptors: D-APV blocked the temporal interactions so that the remaining responses consisted of short-duration EPSPs displaying a lack of summation at this frequency (Fig. $3 A$ ). Similar results were observed in four additional cells tested using the same protocol.

Responses in older neurons consisted of an EPSP followed by an IPSP, both of which were relatively unaffected by application of D-APV $(n=4)$, as illustrated in Figure $3 B$. In the cell of Figure $3 B$, repetitive shock stimulation of the optic tract at $25 \mathrm{~Hz}$ generated several EPSPs overriding the summated IPSPs. The excitatory component of the response to repetitive simulation was not substantially altered by D-APV treatment, although the IPSPs may have been enhanced, perhaps through reduction of a hidden or "occult" NMDA reccptor component in this cell.

\section{Recordings in voltage-clamp mode}

To examine the possible alteration of the voltage dependence or kinetics of NMDA receptors involved in retinogeniculate transmission in developing ferrets, we recorded excitatory postsynaptic currents (EPSCs) in the presence of bicuculline methiodide $(20 \mu \mathrm{M})$ applied to the bathing solution to block $\mathrm{GABA}_{\mathrm{A}}$ receptors. $\mathrm{GABA}_{B}$ receptor-mediated responses were blocked by the intracellular infusion of cesium.

Typical responses to optic tract stimulation at different stages of development are shown in Figure 4. At every age tested, the responses at negative holding potentials near the resting membrane level consisted of an EPSC with rapid onset and decay. At positive holding potentials, in contrast, EPSC decay was very slow and responses typically lasted hundreds of milliseconds. Note that in these examples voltage dependence of the responses remained relatively unaltered during development. This is confirmed by examination of the current versus holding potential plots obtained from the same cells and shown in the lower panels of Figure 4. The early component of the response, defined as the early peak of the EPSC, reversed at approximately 0 to +5 $\mathrm{mV}$ and displayed a striking linear relationship with membrane potential. In contrast, the late component of the EPSC, defined as the amplitude of the response observed $200 \mathrm{msec}$ after its initiation, was linearly related to voltage only at positive holding potentials. The late component of the EPSC exhibited marked attenuation at negative holding potentials, a behavior that reflects the voltage dependence of the NMDA receptor due to $\mathrm{Mg}^{\text {? }}$ block (Nowak ct al., 1984).

Voltage dependency of the optic tract NMDA component. To examine the properties of the NMDA component of the response to optic tract stimulation, in additional experiments the 


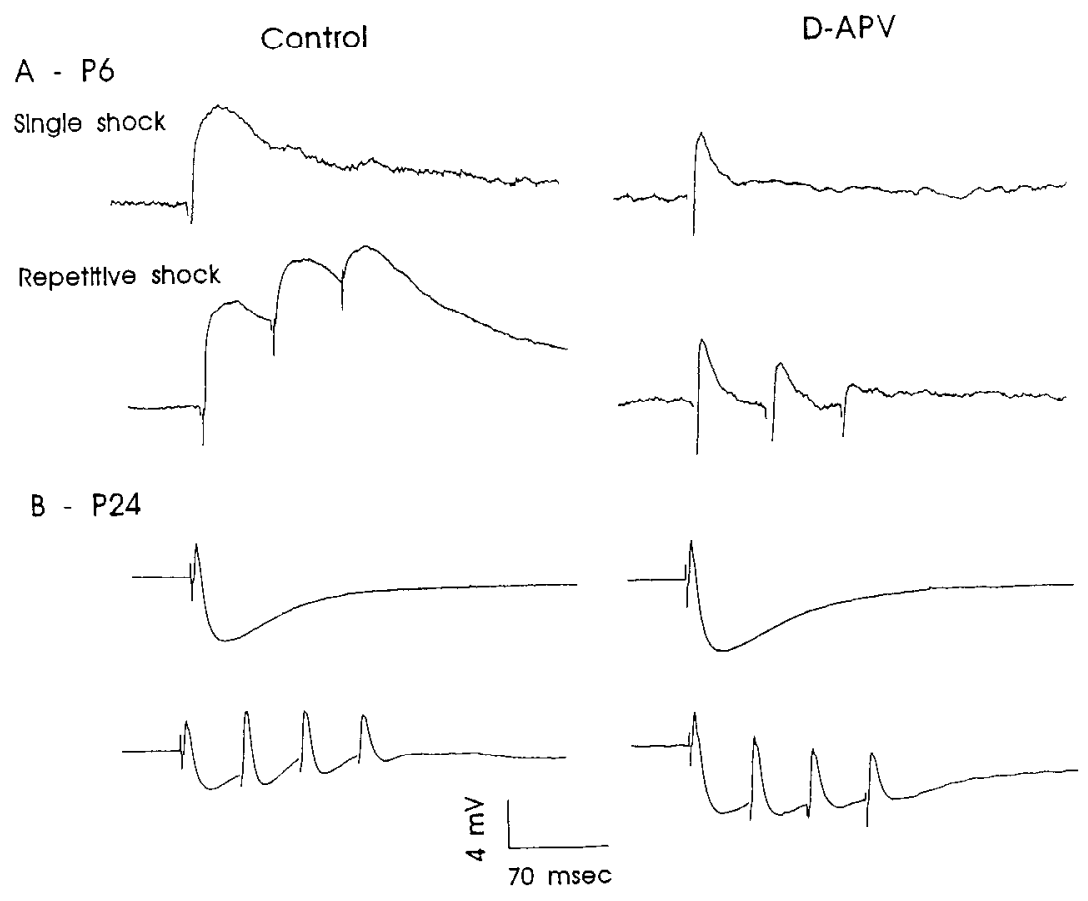

\begin{abstract}
Figure 3. Effects of D-APV on responses of LGNd neurons to single and repetitive stimulation of the optic tract at P6 and P24. A, Application of D-APV at P6 blocked the late component, and decreased the peak amplitude of the response to a single shock. As a result, less depolarization of the membrane was observed in response to repetitive stimulation. $B$, At $\mathrm{P} 24$, excitatory responses remained relatively unaltered after application of D-APV. Recordings were conducted at resting potential levels for both neurons (P6 - $-50 \mathrm{mV} ; \mathrm{P} 24=$ $-62 \mathrm{mV})$.
\end{abstract}

non-NMDA glutamatergic ionotropic receptors were blocked with the antagonist CNQX $(10 \mu \mathrm{M}$ in bath). Responses observed after application of CNQX and bicuculline to the bathing medium are illustrated in the recordings of Figure 5, obtained from P4 and P45 LGNd neurons studied in the presence of bathing medium containing $1.2 \mathrm{mM} \mathrm{Mg}^{2+}$. The non-NMDA antagonist specifically blocked the fast component of the response, an effect especially clear at negative holding potentials (compare with results shown in Fig. 4). The slow component of the response at both negative and positive holding potentials remained unaffected, and could be completely blocked by application of D-APV ( $n=3$, not shown), indicating that transmission at the developing retinogeniculate synapse depends on activation of both NMDA and non-NMDA receptors.

To investigate whether voltage dependence of this pure NMDA response changed with age, $I-V$ plots computed from the re-
P5
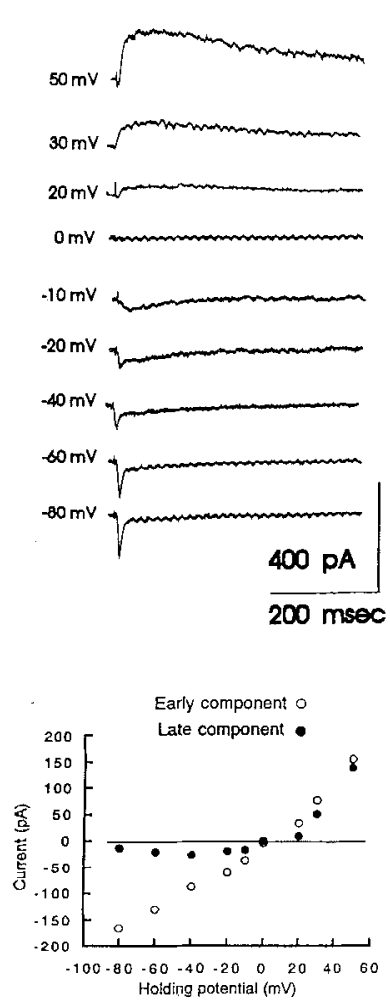

P14
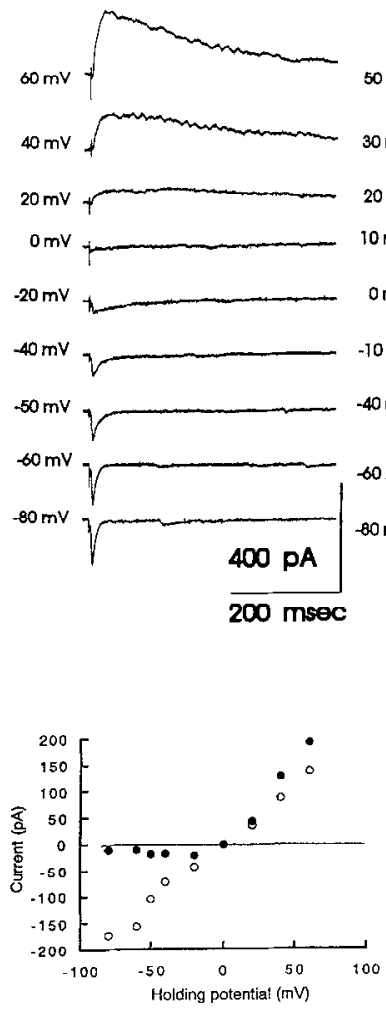

Figure 4. Voltage dependence of early and late components of retinogeniculate EPSCs at different pustiatal ages. Examples of synaptic currents (single sweeps) evoked by optic tract stimulation in LGNd neurons at P5, P14, and P34 are shown in the upper traces. Plots of the early component (peak of the response) and late component (response observed approximately $200 \mathrm{msec}$ after optic tract stimulation) of these responses versus holding potential are shown in the graphs below. Values of the early and late components were obtained by averaging 10 postsynaptic responses at each potential. Note that the $I-V$ plots remained relatively unaltered with age. Recordings were conducted in Ringer's solution containing $4 \mathrm{~mm}$ $\mathrm{MgCl}_{2}$, a concentration used to allow direct comparisons with a previous study showing developmental changes in NMDA-activated responses in the retinocollicular system (Hestrin, 1992). Bicuculline methiodide $(20 \mu \mathrm{M})$ was added in the bathing medium to block $\mathrm{GABA}_{\mathrm{A}}$ receptors. $\mathrm{GABA}_{\mathrm{B}}$-mediated IPSPs were blocked by cesium contained in the recording pipette. 

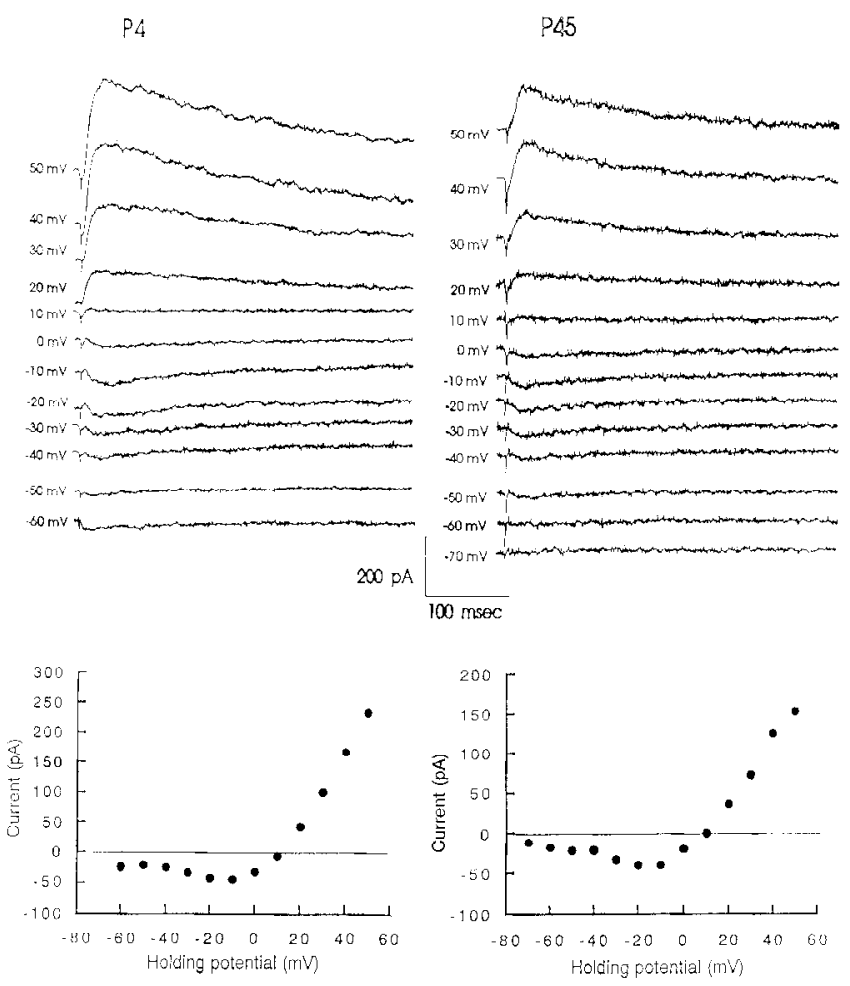

Figure 5. Voltage dependence of NMDA receptor-mediated component of retinogeniculate EPSC in newborn and older animals. Examples of NMDA receptor-mediated synaptic currents (single sweeps) evoked by optic tract stimulation at $\mathrm{P} 4$ and $\mathrm{P} 45$ are shown in top raw data traces. Recordings were conducted in the presence of CNQX $(10 \mu \mathrm{M})$ to block non-NMDA glutanatergic ı eceptors and bicuculline methiodide $(20 \mu \mathrm{M})$ to block $\mathrm{GABA}_{\mathrm{A}}$ receptors. The $\mathrm{GABA}_{13}$ component of the response was blocked by cesium contained in the recording solution. Ihe amplitude of the remaining response was highly dependent on voltage, as shown by the $I-V$ plots below, obtained from the same cells. The values were obtained by averaging 10 postsynaptic responses at each potential. Voltage dependence of the response did not change with age. Recordings were conducted in the presence of physiological concentration (1.2 $\mathrm{mm}$ ) of $\mathrm{MgCl}_{2}$ in the bathing solution.

cordings in Figure 5 are shown in the lower panels. Note the striking similarity in the plots obtained at P4 and P45, suggesting that magnesium blockade of NMD $\Lambda$ receptors is similarly efficient at both ages. Similar $I-V$ plots of the NMDA response obtained in 16 other cells also indicated that the voltage dependency of the NMDA response in LGNd cells did not change substantially with age.

Kinetic properties of the optic tract NMDA component. To examine the kinetic properties of the NMDA response, we recorded from 39 neurons at the holding potential of $+40 \mathrm{mV}$ in the presence of bicuculline and CNQX in the bathing solution. Examples of the recordings that are shown in Figure $6 \mathrm{~A}$ indicate that EPSCs were characterized by a rapid onset and slow decay, these kinetic properties having remained relatively unaltered during the first postnatal month. During the following month, the EPSC duration was shortened, as illustrated in the example of recording from a $\mathrm{P} 45$ animal. The time course of these changes is revealed in the scatter plot of Figure 6 B. Decay time of EPSCs was estimated for each cell as described in Hestrin (1992), by measuring directly the time from the peak of the EPSC to 0.37 of the peak amplitude. The decay time remained relatively stable during the first 40 postnatal days, then decreased abruptly.

\section{Discussion}

Activity-dependent mechanisms, thought to play a major role in the maturation of connectivity in the visual system (for a review, see Constantine-Paton et al., 1990), may be involved in reorganization of retinogeniculate pathways (Shatz and Stryker, 1988). Depending on whether pre- and postsynaptic activities are correlated in time, synapses may be stabilized or deleted (Hebb, 1949; Stent, 1973). conceivably leading to loss of neurites that failed to establish efficient synapses and maintenance of those that effectively drive the postsynaptic neuron. Recently, evidence has been provided that NMDA receptors are involved in Hebhian-type synaptic plasticity in the developing relinogeniculate system; Mooney et al. (1993) reported that persistent enhancement of retinogeniculate transmission can be achieved by bursts of high-frequency synaptic stimulation and that this en hancement appears to depend on NMDA receptor activation. Our results are consistent with the possibility that NMDA receptors may provide a biological substrate for Hebbian-type mechanisms of synaptic plasticity in the developing visual system (Constantine-Paton et al., 1990). Our present findings suggest that NMDA-mediated neuronal response may be enhanced at early stages of development in the ferret's retinogeniculate pathway.

Our results also indicate that several mechanisms may contribute to facilitation of the NMDA response in immature LGNd ncurons: (1) latc maturation of activation of IPSPs may contribute to stronger NMDA-induced ionic currents during the first 3 postnatal weeks; (2) temporal interactions observed in a train of EPSPs elicited by optic tract stimulation can induce more efficient depolarization of the immature neuronal membrane, thus relieving the magnesium blockade of the NMDA receptor (Maycr et al., 1984; Nowak et al., 1984); (3) development of the intrinsic membrane properties in the immature neuron may be coordinated to enhance excitatory transmission related to retinal activity (Ramoa and McCormick, 1994); and (4) finally, the kinetic properties, but not the voltage dependence, of the NMDA response itself may be altered during development so as to increase the duration of the EPSPS. Some of these mechanisms will be discussed separately below.

Late maturation of activation of GABAergic inhibition. Our observations in the mature LGNd are in agreement with previous reports that optic tract stimulation in adult mammals evokes an excitatory monosynaptic potential followed by GA$\mathrm{BA}_{\mathrm{A}}$ - and $\mathrm{GABA}_{\mathrm{B}}$-mediated hyperpolarizing postsynaptic potentials (Crunelli et al., 1988). In contrast, during the first 2 postnatal weeks the typical response to optic tract stimulation consisted of a long-duration EPSP, the late component of which resulted mainly from NMDA receptor--mediated excitation. The decreased efficacy of inhibitory connections thus coincides with the critical period for modifications in retinogeniculate connectivity, and may contribute to enhanced plasticity by allowing an increased level of NMDA receptor-mediated excitation.

The failure of retinal inputs to activate IPSPs in LGNd relay neurons early in development may occur at many sites along the path from retina to interneuron to relay cell. Some of the possibilities include lack of GABAergic interneurons or connections with relay cells, lack of excitation of GABAergic interneurons by retinal fibers, lack of release of GABA during generation of action potentials, and finally, lack of postsynaptic receptor-effector mechanisms for response to release of GABA. At present, data examining the development of these various 


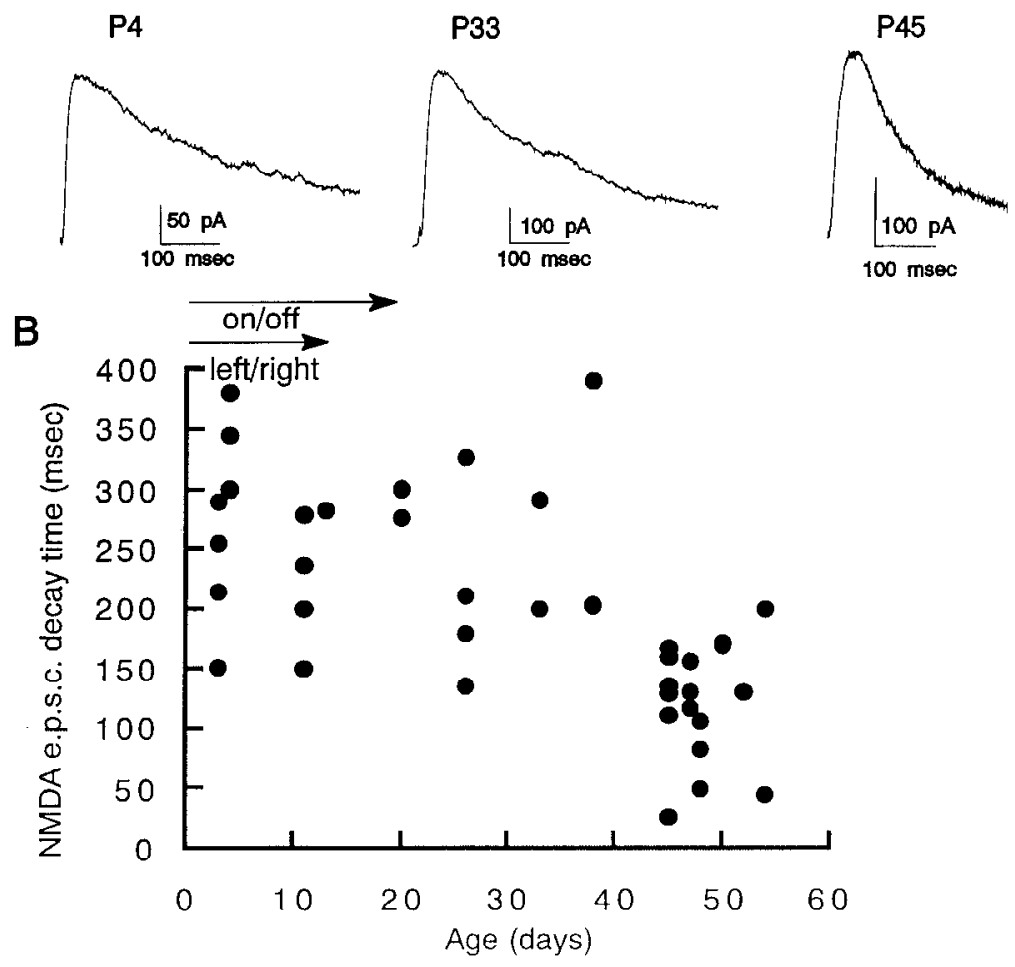

Figure 6. Decay time of NMDA EPSCs recorded in 39 cells. Examples of the recordings at $\mathrm{P} 4, \mathrm{P} 33$, and $\mathrm{P} 45$ are also shown. In these experiments the membrane potential was held at +40 $\mathrm{mV}$ and cells were studied in the presence of CNQX $(4 \mu \mathrm{M})$ and bicuculline methiodide $(50 \mu \mathrm{M})$. As in previous studies in the superior colliculus (Hestrin, 1992), in most immature cells the response could be fit by a single exponential function. In $B$, the time period for segregation of retinal axons into left/ right eye layers (A, $\mathrm{Al}$ ) and on/off-center receptive field types are illustrated (Linden et al., 1981; Hahm et al., 1991). features of GABAergic transmission in the ferret LGNd are not available, although we have preliminary evidence that GABAergic IPSPs in immature LGNd neurons can be observed after single shock stimulation of cortical afferents or direct stimulation of the perigeniculate nucleus (A. S. Ramoa and D. A. McCormick, unpublished observations). The evidence available in other species also indicates that GABA and GABAergic receptors are present in the immature thalamus (Lauder et al., 1986; Bentivoglio et al., 1991). However, thalamic GABAergic mechanisms are known to undergo major changes early in development: the expression of subunit genes for GABA receptors in rat thalamus shows substantial postnatal changes (Laurie et al., 1992), and glutamic acid decarboxylase activity is known to be reduced in the LGNd of neonatal cats, reaching near adult levels during the subsequent 3 postnatal weeks (Fosse et al., 1989). Also consistent with the possibility that GABAergic neurotransmission follows a protracted time course of maturation are the findings that receptive field surround inhibition and spatial resolving power of LGNd neurons in kittens change substantially just before and after eye opening (Daniels et al., 1978; Ikeda and Tremain, 1978). Findings of an early expression of GABA receptors and GABA in several systems, together with results indicating that $G \Lambda B \Lambda$ ergic neurotransmission matures relatively late, have led several authors to propose a role for GABA as a trophic agent during early development (Wolff et al., 1984; Lauder et al., 1986; LoTurco et al., 1991).

Late developmental changes in the efficacy of inhibition is not unique to the developing LGNd, but has also been reported in neocortex (Luhmann and Prince, 1990; Agmon and O'Dowd, 1993; Burgard and Hablitz, 1993), hippocampus (Harris and Teyler, 1983; Mueller et al., 1984; Swann et al., 1989), and piriform cortex (Schwob et al., 1984). Thus, late functional maturation of inhibitory connectivity may represent a general mech- anism to enhance NMDA receptor activation in the developing CNS.

Properties of NMDA-mediated activity during development. In view of the proposed involvement of NMDA receptors in synaptic plasticity, it has been suggested that the greater plasticity characterizing immature synapses results from an altered NMDA neuronal response at early stages of development (Garthwaite et al., 1987; Tsumoto et al., 1987; Ben-Ari et al., 1988; BodeGreuel and Singer, 1989; Tremblay et al., 1989; Kleckner and Dingledine, 1991; Siviy et al., 1991), although other authors disagree (Blanton et al., 1990). Recording from LGNd cells in the voltage-clamp mode, we have directly examined the properties of the NMDA-mediated activity during development of retinogeniculate pathways. Our results show that the voltage dependence of the NMDA response does not change with age, indicating that in this system a lower sensitivity to $\mathrm{Mg}^{2+}$ blockade of NMDA receptors probably does not contribute to the enhanced NMDA responsiveness at early ages. Our results, on the other hand, resemble those reported in the superior colliculus (Hestrin, 1992) and cortex (Carmignoto and Vicini, 1992) in that kinetic properties of the NMDA-induced responses were found to change with age. It is important to note the difference in the time courses of the changes in membrane properties (mostly over by 2-3 weeks), GABAergic inhibition (maturation occurs mainly during the first 3 weeks) and kinetic properties of the NMDA-mediated synaptic responses (which takes place after the first postnatal month). The consequences of these differences are not clear at present, but may be related to additional changes in thalamic connectivity that occur at later ages, such as rearrangements in tectogeniculate projections (Stein et al., 1985).

Although changes in kinetic properties of the NMDA-induced currents were detected here well after the critical period for changes in retinogeniculate connectivity, it is tempting to spec- 
ulate that this represents one additional factor contributing to enhanced synaptic plasticity at early ages. Caution in the interpretation of these results is required, however, since during the first 2 postnatal months, dendritic dimensions and complexity of LGNd neurons increase markedly (Sutton and Brunso-Bechtold, 1991). This correlation in time raises the possibility that the changing kinetic properties of NMDA currents were only apparent, having resulted from space-clamp problems in the recordings obtained from larger neurons. Evidence against this possibility can be found in Figure 6: kinetic properties changed abruptly during the first half of the second postnatal month, while dendritic dimensions and complexity of LGNd neurons increase gradually during this period (Sutton and Brunso-Bechtold, 1991). Moreover, space-clamp problems would be expected to interfere with determination of reversal potential for the NMDA-induced currents. This effect was not observed in the older neurons studied here, as illustrated in the example of Figure 5. Additional experiments, such as single-channel ion current recording and analysis, will be required to examine what mechanisms underlie the changes in kinetic properties of the NMDA response. It will be important to examine, for instance, whether transient subtypes of NMDA receptors contribute to enhanced NMDA-mediated synaptic transmission and synaptic plasticity in the immature retinogeniculate pathway.

\section{References}

Agmon A, O'Dowd DK (1993) NMDA receptor-mediated currents are prominent in the thalamocortical synaptic response before maturation of inhibition. J Neurophysiol 68:345-349.

Ben-Ari Y, Cherubini E, Krnjevic K (1988) Changes in voltage dependence of NMDA currents during development. Neurosci Lett 94: $88-92$.

Bentivoglio M, Spreafico R, Alvarez-Bolado G, Sanchez MP, Fairen A (1991) Differential expression of the $\mathrm{GABA}_{\mathrm{A}}$ receptor complex in the dorsal thalamus and reticular nucleus: an immunohistochemical study in the adult and developing rat. Eur. J Neurosci 3:118-125.

Blanton MG, LoTurco JL, Kriegstcin AR (1990) Endogenous ncurotransmitter activates $N$-methyl-D-aspartate receptors on differentiating neurons in embryonic cortex. Proc Natl Acad Sci USA 87: 8027-8030.

Bode-Greuel KM, Singer W (1989) The development of $N$-methyl-Daspartate receptors in cat visual cortex. Dev Brain Res 46:197-204.

Bowe MA, Victor Nadler JV (1990) Developmental increase in the sensitivity to magnesium of NMDA receptors on CA1 hippocampal pyramidal cells. Dev Brain Res 56:55-61.

Burgard EC, Hablitz JJ (1993) Developmental changes in NMDA and non-NMDA receptor-mediated synaptic potentials in rat neocortex. J Neurophysiol 69:230-240.

Cambray-Deakin MA, Foster AC, Burgoyne RD (1990) The expression of excitatory amino acid binding sites during neuritogenesis in the developing rat cerebellum. Dev Brain Res 54:265-271.

Campbell G, Shatz CJ (1992) Synapses formed by identified retinogeniculate axons during the segregation of eye input. J Neurosci 12 : $1847-1858$.

Carmignoto G, Vicini S (1992) Activity-dependent decrease in NMDA receptor responses during development of the visual cortex. Science 258:1007-1011.

Constantine-Paton M, Cline HT, Debski E (1990) Patterned activity, synaptic convergence and the NMDA receptor in developing visual pathways. Annu Rev Neurosci 13:129-154.

Crunelli V, Haby M, Jasski-Gerschenfeld D, Leresche N, Pirchio M (1988) $\mathrm{Cl}^{-}$and $\mathrm{K}^{+}$dependent inhibitory postsynaptic potentials evoked by interneurons of the rat geniculate nucleus. J Physiol (Lond) 399:153-176.

Daniels JD, Pettigrew JD, Norman JL (1978) Development of singleneuron responses in kitten's lateral geniculate nucleus. J Neurophysiol 41:1373-1393.

Esguerra M, Kwon YH, Sur M (1992) Retinogeniculate EPSPs re- corded intracellularly in the ferret lateral geniculate nucleus in vitro: rolc of NMDA reccptors. Vis Neurosci 8:545-555.

Fosse VM, Heggelund P, Fonnum F (1989) Postnatal development of glutamatergic, GABAergic, and cholinergic neurotransmitter phenotypes in the visual cortex, lateral geniculate nucleus, pulvinar, and superior colliculus in cats. $J$ Neurosci $9: 426-\mathbf{4 3 5}$.

Fox K, Sato H, Daw N (1989) The location and function of NMDA receptors in cat and kitten visual cortex. J Neurosci 9:2443-2454.

Garthwaite G, Yamini B, Garthwaite J (1987) Selective loss of Purkinje and granule cell responsiveness to $N$-methyl-D-aspartate in rat cerebellum during development. Dev Brain Res 36:288-292.

Hahm JO, Langdon RB, Sur M (1991) Disruption of retinogeniculate afferent segregation by antagonists to NMDA receptors. Nature 351 : $568-570$

Harris KM, Teyler TS (1983) Evidence for late development of inhibition in area $\mathrm{C} \Lambda 1$ of the rat hippocampus. Brain Res 268:339 343

Hebb DO (1949) The organization of behavior. New York: Wiley.

Hestrin S (1992) Developmental regulation of NMDA receptor-mediated synaptic currents at a central synapse. Nature 357:686-689.

Hickey TL, Guillery RW (1974) An autoradiographic study of retinogeniculate pathways in the cat and fox. J Comp Neurol 156:239254.

Ikeda $H$, Tremain KE (1978) The development of spatial resolving power of lateral geniculate neurones in kittens. Exp Brain Res 31: 193-206.

Kemp JA, Sillito AM (1982) The nature of the excitatory transmitter mediating $X$ and $Y$ cell inputs to the cat dorsal lateral geniculate nucleus. J Physiol (Lond) 323:377-391.

Kleckner NW, Dingledine R (1991) Regulation of hippocampal NMDA receptors by magnesium and glycine during development. Mol Brain Res 11:151-159.

Lauder JM, Han VKM, Henderson P, Verdoon T, Towle AC (1986) Prenatal ontogeny of the GABAergic system in the rat brain: an immunocytochemical study. Neuroscience 19:465-493.

Laurie DJ, Wisden W, Seeburg PH (1992) The distribution of thirteen $\mathrm{GABA}_{\mathrm{A}}$ receptor subunit mRNAs in the rat brain. III. Embryonic and postnatal development. J Neurosci 12:4151-4172.

Linden DC, Guillery RW, Cucchiaro J (1981) The dorsal lateral geniculate nucleus of the normal ferret and its postnatal development. J Comp Neurol 203:189-211

LoTurco JJ, Blanton MG, Krigstein AR (1991) Initial expression and endogenous activation of NMDA channels in early neocortical development. J Neurosci 1 1:792-799.

Luhmann HJ, Prince DA (1990) Control of NMDA receptor-mediated activity by GABAergic mechanisms in mature and developing rat neocortex. Dev Brain Res 54:287-290.

Mayer ML, Westbrook GL, Guthrie PB (1984) Voltage-dependent block by $\mathrm{Mg}^{++}$of NMDA responses in spinal cord neurones. Nature 309:261-263.

Mooney R, Madison DV, Shatz C (1993) Enhancement of transmission at the developing retinogeniculate synapse. Neuron 10:815-825.

Morrisett RA, Mott DD, Lewis DV, Wilson WA, Swartzwelder HA (1990) Reduced sensitivity of the $N$-methyl-D-aspartate component of synaptic transmission to magnesium in hippocampal slices from immature rats. Dev Brain Res 56:257-262.

Mueller AL, Taube JS, Schwartzkroin PA (1984) Development of hyperpolarizing inhibitory postsynaptic potentials and hyperpolarizing responses to $\gamma$-aminobutyric acid in rabbit hippocampus studied in vitro. J Neurosci 4:860-867.

Nowak L, Bregestovski P, Ascher P, Herbert A, Prochiantz A (1984) Magnesium gates glutamate-activated channels in mouse central neurons. Nature 307:462-465.

Rakic $P$ (1976) Prenatal genesis of connections subserving ocular dominance in the rhesus monkey. Nature 261:467-471.

Ramoa AS, McCormick D (1992) Development of electrophysiological membrane properties and synaptic responses of ferret LGNd cells. Soc Neurosci Abstr 18:923.

Ramoa AS, McCormick DA (1994) Developmental changes in electrophysiological properties of LGNd neurons during reorganization of retinogeniculate connections. J Neurosci 14:2089-2097.

Scharfman HE, Lu SM, Guido W, Adams PR, Sherman SM (1990) $N$-methyl-D-aspartate receptors contribute to excitatory postsynaptic potentials of cat lateral geniculate neurons recorded in thalamic slices. Proc Natl Acad Sci USA 87:4548-4552. 
Schwob JE, Haberly LB, Price JL (1984) The development of physiological responses of the pirform cortex in rats to stimulation of the lateral olfactory tract. J Comp Neurol 223:223-237.

Shatz CJ (1983) The prenatal development of the cat's retinogeniculate pathway. J Neurosci 3:482-499.

Shatz CJ, Stryker MP (1988) Prenatal tetrodotoxin infusion blocks segregation of retinogeniculate afferents. Science 242:87-89.

Siviy SM, Buchwald NA, Levine MS (1991) Enhanced responses to NMDA receptor activation in the developing cat caudate nucleus. Neurosci Lett 132:77-81

Stein BE, McHoffie JG, Harting JK, Huerta MF, Hashikawa T (1985) Transient tectogeniculate projection in neonatal kittens: an autoradiographic study. J Comp Neurol 239:402-412.

Stent GS (1973) A physiological mechanism for Hebb's postulate of learning. Proc Natl Acad Sci USA 70:997-1001.

Stryker MP, Zahs KR (1983) On and Ofr sublaminae in the lateral geniculate nucleus of the ferret. J Neurosci 3:1943-1951.
Sutton JK, Brunso-Bechtold JK (1991) A Golgi study of dendritic development in the dorsal lateral geniculate nucleus of normal ferrets. J Comp Neurol 309:71-85.

Swann JW, Brady RJ, Martin DL (1989) Postnatal development of GABA-mediated synaptic inhibition in rat hippocampus. Neuroscience 28:551-561.

Tremblay E, Roisin MP, Repesa A, Charriaut-Marlangue C, Ben-Ari $Y$ (1989) Transient increased density of NMDA binding sites in the developing rat hippocampus. Brain Res 461:393-396.

Tsumoto $T$, Hagihara $K$, Sato $H$, Hata $Y$ (1987) NMDA receptors in the visual cortex of young kittens are more effective than those of adult cats. Nature 327:513-515.

Wolff JR, Bottcher H, Zetzsche T, Oertel WH, Chronwall BM (1984) Development of GABAergic neurons in the rat visual cortex as identified by glutamate decarboxylase-like immunoreactivity. Neurosci Lett 47:207-212. 